\title{
Goals in the conceptual coherence of social categories
}

\author{
STEPHEN J. READ, LYNN C. MILLER, and DAVID K. JONES \\ University of Southern California, Los Angeles, California
}

\begin{abstract}
Many traits are goal-derived categories in which the goals associated with the traits help define the typicality structure of the trait categories. Consistent with this hypothesis, subjects' ratings of the extent to which trait-related behaviors achieved the goals associated with the traits strongly predicted the rated typicality of the behaviors. In addition, the confidence with which people made trait inferences from behaviors was highly predicted by how strongly the behaviors were related to the goals associated with the traits. Goals play a central role in the conceptual coherence of traits and other social categories.
\end{abstract}

What is a trait? Psychologists have long argued over this question, without any apparent resolution. Recently we have suggested that many traits are goal-based structures consisting of four components: (1) goals, (2) plans, (3) resources, and (4) beliefs (Miller \& Read, 1987, in press; Read \& Miller, 1989). Moreover, we believe that the goals associated with these traits are responsible for the traits' coherence as conceptual categories (see also Alston, 1975; John, 1986). Other theorists have also argued that goals or related concepts such as needs or motives are central to conceptions of traits (e.g., Allport, 1937; Alston, 1970, 1975; Carbonell, 1979; Cattell, 1965; John, 1986; Mischel, 1973; Murray, 1938; Pervin, 1983).

The idea of traits as goal-based structures differs from the most widely accepted view of the conceptual structure of traits which is a prototype model in which the goodness or typicality of trait category members is based on their family resemblance (e.g., Buss \& Craik, 1983; Cantor \& Mischel, 1977, 1979). According to this model, members of a trait category vary in typicality, with some members being better examples of the trait than others. These authors have followed Rosch $(1975,1978$; Rosch \& Mervis, 1975) in arguing that the typicality structure of categories is based on family resemblance, which is a function of the average similarity of an exemplar to other members of the category and its dissimilarity to members of contrasting categories. Thus, according to this conception of traits, the conceptual structure of traits and their coherence is based on the similarity of exemplars to one another.

However, there are several problems with this notion of traits. One problem is empirical. Buss and Craik (1983) note that behaviors that are highly typical of the same trait are often not topographically or physically similar to one another. If this is true, it suggests that family resemblance,

\footnotetext{
We wish to thank David Buss for providing us with the behaviors and ratings used in this study. Correspondence should be addressed to Stephen J. Read, Department of Psychology, University of Southern California, Los Angeles, CA 90089-1061.
}

which is based on judgments of physical similarity, may not be responsible for the typicality structure of trait categories.

A second problem is theoretical. Murphy and Medin (1985; see also Wattenmaker, Nakamura, \& Medin, 1988) have argued that similarity-based notions of conceptual coherence are inadequate. To say that items belong to the same category simply because they are similar to one another is insufficient, because it begs the questions of why some features are more important than others and of what should count as a feature. We still need to know why those features are important.

But if family resemblance is not responsible for the coherence of traits, what is? Murphy and Medin (1985) argue that category coherence depends on a theory that interrelates the features characterizing that category. We suggest that the coherence of social categories for people, situations, and events depends on theories about associated goals and plans.

But if this is so, how would we provide empirical evidence for this position? One possible answer is suggested by Barsalou's (1985) recent work on goal-derived categories. He has recently distinguished two kinds of categories: taxonomic and goal-derived. Taxonomic categories are exemplified by object categories, such as birds, furniture, and so forth. Typicality for taxonomic categories seems to be based on family resemblance. In contrast, goal-derived categories hang together because of a goal or ideal. Here the typicality or goodness of a category member is defined by its relation to the goal or ideal of the category. For example, how might wedding pictures, stereo, and cat hang together as members of the same category? Barsalou (1985) suggests that they are members of the category things to take out of the house in case of a fire and that they hang together because they are things of value we wish to save from destruction.

We suggest that traits are one important kind of goalbased category in which the goals associated with trait categories define the trait categories' typicality structure. Because trait-related behaviors are one kind of trait 
category member, we predict that the typicality of traitrelated behaviors is strongly correlated with the strength of their relation to the goals of the trait. In contrast, the family resemblance of a behavior should not predict its typicality, unless it turns out that the goals of behaviors play a major role in people's judgments of the similarity of the behaviors.

One reason we are interested in the typicality of traitrelated behaviors is that the typicality of a behavior should affect the confidence with which people make trait inferences from it (Buss \& Craik, 1983; Cantor \& Mischel, 1979). The more typical a behavior is of a trait, the more confident we should be that the individual who performed the behavior can be described by the trait. If the typicality of trait-related behaviors is based on how strongly the behaviors are related to the goals of the trait, then the confidence with which people make trait inferences from a behavior should be strongly associated with how closely tied the behavior is to the goals of the trait.

In summary, our predictions are the following: (1) The degree to which behaviors are related to the goals associated with a trait (goal-relatedness) should predict the typicality of the behaviors. (2) The family resemblance of a behavior should not predict its typicality, unless similarity on goals is a large part of family resemblance. (3) The goal-relatedness of a behavior should predict the confidence of a trait inference from it.

\section{METHOD}

\section{Subjects}

Participants were 6 graduate and 156 undergraduate students at the University of Southern California, the latter of whom participated for extra credit in introductory psychology.

\section{Procedure}

We used six traits and their related behaviors from Buss and Craik's (1983) act frequency approach to the measurement of personality. According to this approach, one can measure the extent to which a trait is a good description of someone by tallying the frequency with which the individual performs behaviors typical of the trait.

The six traits fall into three pairs of opposites: gregarious-aloof, dominant-submissive, and quarrelsome-agreeable. For each trait, Buss and Craik (1983) developed a list of 100 behaviors and had each behavior rated for how typical it was of someone with that trait. The 100 behaviors vary from very typical to not at all typical. To make our rating task more manageable for the subjects, we selected 50 behaviors from each set of 100 by rank ordering the behaviors by typicality and then choosing every other one. Buss and Craik's typicality ratings were used as the measure of typicality.

We then generated two goals for each trait. First, six colleagues were asked to list what they thought were the most important goals of someone with each of the six traits. Frequency of mention was then tabulated, with semantically equivalent goals being treated as the same goal. From these listings we then created a list of 18 goals for each trait, containing both goals that had been frequently mentioned for that trait and goals mentioned for other traits. Another group then rated, on a 9-point scale, how characteristic each of the goals was for an individual possessing that trait. A rating of 9 indicated that the goal was extremely characteristic of someone with that trait. For all the traits, with the exception of aloof, we then chose two goals with ratings of 8 or better on the 9-point scale. We tried as much as possible to choose goals that were different from one another. For aloof, none of the goals was rated above an 8, so we ended up with two goals rated at 7.33. The two goals used for each trait were gregarious-being with other people and making friends; aloof-avoiding intimacy with others and avoiding involvement with others; dominant-controlling other people and getting one's own way; submissive-avoiding conflict or confrontation with others and avoiding rejection by others; quarrelsome-confrontation with others and winning arguments; agreeable-being liked and pleasing others.

We then gathered the following ratings for each trait; each of the rating tasks was done by a different group of subjects, with each rater providing ratings for all six traits.

Typicality judgments. For these, we simply used the average typicality of each behavior as gathered by Buss and Craik (1983).

Goal-relatedness of behaviors. We had identified 2 goals for each trait, for a total of 12 goals. The 12 goals were divided into two sets of 6 , with a goal for each of the traits in each set. Each goal was then printed at the top of a sheet of paper, followed by the 50 behaviors that were associated with the trait associated with the goal. Raters used a 9-point scale to indicate the extent to which each behavior achieved the outcome or goal listed at the top of the page. Each rater rated the associated behaviors for each of the 6 goals in a set for a total of 300 ratings. The first set of goal ratings was done by 26 raters and the second set by 18 raters.

Family resemblance ratings. One way to compute family resemblance ratings would be to have subjects rate how similar each of the 50 behaviors for a trait was to every other one of the 50 behaviors. However, this would require subjects to make 1,225 comparisons for each of the six traits, for a total of 7,350 comparisons. Thus, we used a simpler method that provided a good approximation to family resemblance. Barsalou (1985) has observed that a measure of family resemblance based on average interitem similarity should closely approximate a measure based on the similarity of members to the central tendency of the category. This suggested that we could approximate family resemblance by having subjects rate the similarity of the behaviors to the most prototypical members of the category.

To do this, we identified the four most prototypical behaviors for each trait and then had each of four sets of raters rate how similar each of the listed behaviors was to a different one of the four most prototypical behaviors listed at the top of the page. Each rater did this for one of the prototypical behaviors for each trait, using a 9-point scale ranging from 1 (not at all similar) to 9 (extremely similar). We then averaged the similarity ratings across the four sets of raters so that we arrived at a measure of the average similarity of the behaviors to the four most prototypical behaviors. There were 20 raters for each of the four forms of the questionnaire.

Although this may seem like a somewhat unusual way to measure family resemblance, as we will see the results make sense. We used four prototypical behaviors, because this provided a reasonable tradeoff between getting enough ratings to get a stable estimate and not using so many prototypical behaviors that we needed to use less typical behaviors.

Confidence of trait inferences. Nineteen raters received a questionnaire with the six traits and their associated behaviors. For each of the 50 behaviors in the set, the raters indicated how confident they would be that an individual who performed that behavior possessed the trait listed at the top of the page. The ratings were made on a 9point scale ranging from 1 (not at all confident) to 9 (very confident).

\section{RESULTS}

All of the variables in the following analyses are based on the average rating, across raters, of each behavior on that particular variable. That is, we analyzed the mean typicality of each behavior, the mean goal-relatedness of each behavior for each of two goals, the mean family resemblance, and the mean trait-inference confidence. 
All of our reliabilities, as measured by Cronbach's alpha, were quite high, ranging from .80 to the low .90 s, with three exceptions in the .70s. All of Buss and Craik's (1983) reliabilities were .90 and above.

\section{Prediction of Typicality}

As predicted, the goal-relatedness of a behavior strongly predicted its typicality. With both goals entered into a mul- tiple regression equation, the multiple $R$ s for the six traits run from a low of .61 for agreeable to .78 for aloof, with the multiple $R$ s for all the traits, except agreeable, above .70 (see Table 1). In addition, $R^{2}$ indicates that for all the traits but agreeable, the two goals together account for $47 \%$ or more of the variance. These regressions also indicate that for both orders of entry of the two goals, the goal that is entered second still accounts for significant

Table 1

$R, R^{2}$, and $R^{2}$ Change from Regression of Typicality of Behaviors on Goal-Relatedness of Behaviors and Similarity: Separate Hierarchical Regressions for Each Trait, with Variables Entered Separately in the Listed Order

\begin{tabular}{|c|c|c|c|c|c|c|}
\hline & Gregarious & Aloof & Dominant & Submissive & Quarrelsome & Agreeable \\
\hline \multicolumn{7}{|c|}{ First Set } \\
\hline \multicolumn{7}{|l|}{ Goal 1} \\
\hline $\boldsymbol{R}$ & .628 & .740 & .691 & .701 & .704 & .603 \\
\hline$R^{2}$ & .394 & .548 & .477 & .491 & .495 & .363 \\
\hline Change & $.394 \ddagger$ & $.548 \ddagger$ & $.477 \ddagger$ & $.491 \ddagger$ & $.495 \ddagger$ & $.363 \ddagger$ \\
\hline \multicolumn{7}{|l|}{ Goal 2} \\
\hline$R$ & .685 & .781 & .731 & .744 & .736 & .609 \\
\hline$R^{2}$ & .469 & .609 & .534 & .554 & .541 & .371 \\
\hline Change & $.075^{*}$ & $.061 *$ & $.057 *$ & $.062 *$ & $.046 *$ & .007 \\
\hline \multicolumn{7}{|l|}{ Similarity } \\
\hline $\boldsymbol{R}$ & .807 & .894 & .774 & .865 & .825 & .741 \\
\hline$R^{2}$ & .652 & .799 & .599 & .749 & .681 & .549 \\
\hline Change & $.183 \ddagger$ & $.190 \ddagger$ & $.065+$ & $.195 \ddagger$ & $.140 \ddagger$ & $.178 \ddagger$ \\
\hline \multicolumn{7}{|c|}{ Second Set } \\
\hline \multicolumn{7}{|l|}{ Goal 2} \\
\hline$R$ & .669 & .731 & .635 & .590 & .236 & .567 \\
\hline$R^{2}$ & .448 & .534 & .403 & .348 & .056 & .322 \\
\hline Change & $.448 \ddagger$ & $.534 \ddagger$ & $.403 \ddagger$ & $.348 \ddagger$ & .056 & $.322 \ddagger$ \\
\hline \multicolumn{7}{|l|}{ Goal 1} \\
\hline $\boldsymbol{R}$ & .685 & .780 & .731 & .744 & .736 & .609 \\
\hline$R^{2}$ & .469 & .609 & .534 & .554 & .541 & .371 \\
\hline Change & .021 & $.075 \dagger$ & $.131 \ddagger$ & $.206 \ddagger$ & $.486 \ddagger$ & $.049 \S$ \\
\hline \multirow[t]{2}{*}{ Similarity } & \multicolumn{6}{|c|}{ (Same as in First Set) } \\
\hline & \multicolumn{6}{|c|}{ Third Set } \\
\hline Similarity & & & & & & \\
\hline$R$ & .797 & .878 & .763 & .862 & .717 & .704 \\
\hline$R^{2}$ & .635 & .770 & .582 & .744 & .514 & .496 \\
\hline Change & $.635 \ddagger$ & $.770 \ddagger$ & $.582 \ddagger$ & $.744 \ddagger$ & $.514 \ddagger$ & $.496 \ddagger$ \\
\hline \multicolumn{7}{|l|}{ Goal 1} \\
\hline$R$ & .804 & .894 & .771 & .865 & .825 & .741 \\
\hline$R^{2}$ & .647 & .799 & .594 & .748 & .681 & .549 \\
\hline Change & .012 & $.029 *$ & .012 & .005 & $.167 \ddagger$ & $.053^{*}$ \\
\hline \multicolumn{7}{|l|}{ Goal 2} \\
\hline$R$ & .807 & .894 & .774 & .865 & .825 & .741 \\
\hline$R^{2}$ & .652 & .799 & .599 & .749 & .681 & .549 \\
\hline Change & .005 & .000 & .005 & .000 & .000 & .000 \\
\hline
\end{tabular}

Fourth Set

Similarity

(Same as in Third Set)

Goal 2

\begin{tabular}{lllllll}
$R$ & .806 & .880 & .767 & .863 & .721 & .727 \\
$R^{2}$ & .650 & .775 & .588 & .745 & .520 & .529 \\
Change & .015 & .004 & .006 & .001 & .006 & $.033 \S$ \\
$\begin{array}{llllll}\text { Goal } 1 \\
R\end{array}$ & & & & & & \\
$R$ & .807 & .894 & .774 & .865 & .825 & .741 \\
$R^{2}$ & .652 & .799 & .599 & .749 & .681 & .549 \\
Change & .002 & $.025 *$ & .010 & .004 & $.161 \ddagger$ & .020 \\
\hline
\end{tabular}

${ }^{*} p<.05 . \quad \dagger p<.01 . \quad \ddagger p<.001 . \quad \S p<.10$. 
additional variance, after controlling for the contribution of the first goal. However, the first goal entered clearly accounts for most of the variance.

Once the effects of goal-relatedness are taken into account, does similarity still predict typicality? The answer is yes. When similarity is entered after the goal-relatedness ratings, it still accounts for additional variance of between $7 \%$ and $20 \%$, depending on the trait.

But what happens when similarity is entered before the goal-relatedness ratings? How well does similarity predict, and does goal-relatedness still predict? When similarity is entered first, the multiple $R$ ranges from .70 to .88 and the $R^{2}$ ranges from .50 to .77 . After similarity is entered, goal-relatedness explains significant additional variance for aloof, quarrelsome, and agreeable, but the amount is substantial only for quarrelsome, $17 \%$.

These analyses, and the high simple correlations between similarity and goal-relatedness, indicate that the similarity and goal-relatedness ratings share considerable variance. Perhaps, when assessing the similarity of behaviors to the prototypical behaviors, raters were assessing the extent to which the behaviors achieved a similar goal or outcome. If the goals of a behavior are critical to its meaning, raters might be expected to attend to the goals of a behavior in assessing its similarity.
Consistent with this reasoning, a series of multiple regressions indicated that the goal-relatedness of behaviors strongly predicts the similarity measure (see Table 2 ). With the two goal-relatedness measures as predictors, the multiple $R$ s range from .62 for agreeable to .88 for dominant.

To gather further evidence that goals were important in the perceived similarity of two behaviors, we had additional subjects rate the extent to which the behaviors achieved the same goals as the prototypical behaviors. If the raters judging similarity were evaluating whether the behavior had goals similar to the prototypical behavior, then these new ratings ought to have been strongly correlated with both the similarity ratings and the goalrelatedness ratings. To gather these new ratings, for each of the two most prototypical behaviors, the subjects were asked to rate how likely the other behaviors would be to achieve the same outcome as the behavior (one of the prototypical ones) listed at the top of the sheet.

This measure of common outcomes is strongly correlated with the similarity measures, ranging from a high of .89 for aloof to .55 for agreeable (see Table 3). This measure is also strongly correlated with the goalrelatedness ratings, ranging from roughly .60 to .85 , with the exception of the goal-relatedness ratings for agree-

Table 2

$R, R^{2}$, and $R^{2}$ Change for Regression of Similarity on the Two Goal-Relatedness Ratings: Different Regressions for Different Traits, with Variables Entered Separately in Listed Order

\begin{tabular}{|c|c|c|c|c|c|c|}
\hline & Gregarious & Aloof & Dominant & Submissive & Quarrelsome & Agreeable \\
\hline \multicolumn{7}{|c|}{ First Set } \\
\hline Goal 1 & & & & & & \\
\hline$R$ & .688 & .707 & .825 & .762 & .482 & .592 \\
\hline$R^{2}$ & .473 & .500 & .681 & .581 & .232 & .350 \\
\hline Change & $.473 \ddagger$ & $.500 \ddagger$ & $.681 \ddagger$ & $.581 \ddagger$ & $.232 \ddagger$ & $.350 \ddagger$ \\
\hline \multicolumn{7}{|l|}{ Goal 2} \\
\hline$R$ & .753 & .801 & .876 & .814 & .635 & .616 \\
\hline$R^{2}$ & .566 & .641 & .768 & .663 & .404 & .380 \\
\hline Change & $.093 \dagger$ & $.140 \ddagger$ & $.086 \ddagger$ & $.082 \dagger$ & $.172 \ddagger$ & .029 \\
\hline \multicolumn{7}{|c|}{ Second Set } \\
\hline$R$ & .737 & .786 & .765 & .653 & .428 & .600 \\
\hline$R^{2}$ & .542 & .617 & .585 & .426 & .183 & .360 \\
\hline Change & $.542 \ddagger$ & $.617 \ddagger$ & $.585 \ddagger$ & $.426 \ddagger$ & $.183 \ddagger$ & $.360 \ddagger$ \\
\hline \multicolumn{7}{|l|}{ Goal 1} \\
\hline$R$ & .753 & .801 & .876 & .814 & .635 & .616 \\
\hline$R^{2}$ & .566 & .641 & .768 & .662 & .404 & .380 \\
\hline Change & .024 & $.024 \S$ & $.183 \ddagger$ & $.236 \ddagger$ & $.221 \ddagger$ & $.020 \ddagger$ \\
\hline
\end{tabular}

${ }^{*} p<.05 . \quad \dagger p<.01 . \ddagger p<.001 . \quad \S p<.10$.

Table 3

Correlation Between Shared Outcome Measure and Similarity, Goal-Relatedness, and Prototypicality, for Each Trait

\begin{tabular}{lcccccc}
\hline & Gregarious & Aloof & Dominant & Submissive & Quarrelsome & Agreeable \\
\hline Similarity & .85 & .89 & .66 & .82 & .72 & .55 \\
Goal 1 & .76 & .67 & .70 & .66 & .74 & .26 \\
Goal 2 & .85 & .83 & .57 & .62 & -.12 & .37 \\
Prototypicality & .70 & .77 & .47 & .68 & .72 & .50 \\
\hline
\end{tabular}

Note-All correlations greater than .27 are significant at $p<.05$ for a two-tailed test. 
able, which are around .30 . The strong relation of the measure of common outcomes to both similarity and goalrelatedness and the relation between goal-relatedness and similarity strongly suggest that when subjects were judging the similarity of behaviors, a major component of the task consisted of judging whether the two behaviors achieved the same goal. Thus, it seems quite likely that goals are important to the perceived similarity of behaviors.

\section{Confidence of Trait Inferences}

We performed a set of multiple regressions to assess the independent contributions of goal-relatedness and similarity to the confidence of trait inferences. The goal ratings entered first strongly predict the confidence of trait inferences for all of the traits but agreeable (see Table 4). The multiple $R$ s range from .68 for quarrelsome to .86 for aloof and account for anywhere from $47 \%$ to $74 \%$ of the variance. In addition, each of the two goal ratings

Table 4

$R, R^{2}$, and $R^{2}$ Change for Regressions of Confidence of Trait Inference on Predictor Variables: Separate Hierarchical Regressions for Each Trait, with Variables Entered Separately in Listed Order

\begin{tabular}{|c|c|c|c|c|c|c|}
\hline & Gregarious & Aloof & Dominant & Submissive & Quarrelsome & Agreeable \\
\hline \multicolumn{7}{|c|}{ First Set } \\
\hline Goal 1 & & & & & & \\
\hline $\boldsymbol{R}$ & .785 & .646 & .693 & .767 & .624 & .266 \\
\hline$R^{2}$ & .617 & .418 & .480 & .488 & .389 & .071 \\
\hline Change & $.617 \ddagger$ & $.418 \ddagger$ & $.480 \ddagger$ & $.588 \ddagger$ & $.389 \ddagger$ & $.071 \S$ \\
\hline \multicolumn{7}{|l|}{ Goal 2} \\
\hline$R$ & .816 & .858 & .777 & .799 & .682 & .324 \\
\hline$R^{2}$ & .666 & .736 & .603 & .639 & .466 & .105 \\
\hline Change & $.049 *$ & $.318 \ddagger$ & $.123 \ddagger$ & $.151^{*}$ & $.076^{*}$ & .034 \\
\hline \multicolumn{7}{|l|}{ Similarity } \\
\hline $\boldsymbol{R}$ & .952 & .882 & .883 & .926 & .728 & .614 \\
\hline$R^{3}$ & .906 & .778 & .780 & .857 & .530 & .377 \\
\hline Change & $.240 \ddagger$ & $.042 \dagger$ & $.177 \ddagger$ & $.218 \ddagger$ & $.065^{*}$ & $.272 \ddagger$ \\
\hline \multicolumn{7}{|c|}{ Second Set } \\
\hline \multicolumn{7}{|l|}{ Goal 2} \\
\hline & .767 & .857 & .720 & .605 & .258 & .323 \\
\hline$R^{2}$ & .588 & .735 & .519 & .366 & .066 & .104 \\
\hline Change & $.588 \ddagger$ & $.735 \ddagger$ & $.519 \ddagger$ & $.366 \ddagger$ & $.066 \S$ & $.104^{*}$ \\
\hline \multicolumn{7}{|l|}{ Goal 1} \\
\hline & .816 & .858 & .777 & .799 & .682 & .324 \\
\hline$R^{2}$ & .666 & .736 & .603 & .639 & .466 & .105 \\
\hline Change & $.078 \dagger$ & .001 & $.084 \dagger$ & $.273 \ddagger$ & $.399 \ddagger$ & .001 \\
\hline \multirow[t]{2}{*}{ Similarity } & \multicolumn{6}{|c|}{ (Same as in First Set) } \\
\hline & \multicolumn{6}{|c|}{ Third Set } \\
\hline \multicolumn{7}{|l|}{ Similarity } \\
\hline & .930 & .791 & .878 & .920 & .383 & .600 \\
\hline$R^{2}$ & .866 & .626 & .771 & .846 & .147 & .360 \\
\hline Change & $.866 \ddagger$ & $.626 \ddagger$ & $.771 \ddagger$ & $.847 \ddagger$ & $.147 \dagger$ & $.360 \ddagger$ \\
\hline \multicolumn{7}{|l|}{ Goal 1} \\
\hline $\boldsymbol{R}$ & .952 & .801 & .880 & .926 & .631 & .610 \\
\hline$R^{2}$ & .906 & .641 & .774 & .857 & .398 & .372 \\
\hline Change & $.040 \ddagger$ & .015 & .003 & .010 & $.251 \ddagger$ & .012 \\
\hline \multicolumn{7}{|l|}{ Goal 2} \\
\hline $\boldsymbol{R}$ & .952 & .882 & .883 & .926 & .728 & .614 \\
\hline $\boldsymbol{R}^{2}$ & .906 & .778 & .780 & .857 & .531 & .377 \\
\hline Change & .000 & $.136 \ddagger$ & .006 & .000 & $.132 \ddagger$ & .005 \\
\hline \multicolumn{7}{|c|}{ Fourth Set } \\
\hline Similarity & \multicolumn{6}{|c|}{ (Same as in Third Set) } \\
\hline \multicolumn{7}{|l|}{ Goal 2} \\
\hline $\boldsymbol{R}$ & .938 & .878 & .881 & .920 & .604 & .602 \\
\hline$R^{2}$ & .880 & .771 & .777 & .847 & .365 & .362 \\
\hline Change & $.014^{*}$ & $.145 \ddagger$ & .006 & .000 & $.218 \ddagger$ & .002 \\
\hline \multicolumn{7}{|l|}{ Goal 1} \\
\hline$R$ & .952 & .882 & .883 & .926 & .728 & .614 \\
\hline$R^{2}$ & .906 & .778 & .780 & .857 & .531 & .377 \\
\hline Change & $.026 \ddagger$ & .007 & .004 & $.010 \S$ & $.166 \ddagger$ & .015 \\
\hline
\end{tabular}

${ }^{*} p<.05 . \quad \dagger p<.01 . \quad \ddagger p<.001 . \quad \S p<.10$. 
accounts for unique variance after controlling for the other. However, the multiple $R$ for agreeable was only .32 , and it accounts for only $11 \%$ of the variance. As in the analyses of typicality, similarity accounts for additional variance when it is entered after the goal ratings, adding anywhere between $4 \%$ and $27 \%$.

In a final set of analyses, similarity was entered first, followed by the two goal ratings. Similarity entered first accounts for a substantial proportion of the variance, with multiple $R \mathrm{~s}$ ranging from .60 for agreeable to .93 for gregarious, and with variance accounted for ranging from $36 \%$ to $87 \%$. The only exception to these high values was quarrelsome, with a multiple $R$ of .38 and an $R^{2}$ of .15 . After similarity is entered, the goal ratings account for additional significant variance, although the amounts are relatively small.

Although similarity entered first accounts for a larger proportion of variance than goal-relatedness entered first, nevertheless goal-relatedness entered first predicts a very large proportion of the variance. In fact, when goalrelatedness is entered first, the additional variability predicted by similarity is quite a bit smaller than that for goal-relatedness. Parallel to our argument for the results on typicality, similarity may predict the confidence of trait inferences so strongly because a major part of judging similarity among behaviors may be the evaluation of whether or not the two behaviors share the same goal.

\section{DISCUSSION}

As expected, the goal-relatedness of a behavior strongly predicted both its typicality and the confidence with which people would make a trait inference from it. Although the similarity of a behavior to prototypical behaviors also strongly predicted its typicality and the confidence of trait inferences made from it, several pieces of evidence indicate that this probably occurred because similarity of goals was an important part of the similarity judgment. First, the similarity of the behavior was strongly correlated with its goal-relatedness. Second, the similarity of the behavior to the central tendency was strongly correlated with judgments of whether or not the behavior achieved the same goal as prototypical behaviors. Third, the multiple regressions predicting typicality and confidence indicate that the goal-relatedness and similarity ratings share a large amount of variance in predicting typicality and confidence.

In contrast, Barsalou's (1985) investigation of goalderived categories resulted in the finding that goal-ratings were a much better predictor of typicality than family resemblance was. One possible reason for this discrepancy is that for Barsalou's goal-derived categories, the goals to which objects were related may not have been salient when subjects were judging similarity. In contrast, when subjects were judging the similarity of behaviors, the goals of the behaviors might have been highly salient because the goals of an action are often a central part of its meaning.

Consistent with this reasoning, Barsalou (1985) has suggested that goal-derived categories are typically, "not very salient and do not stand out as natural groups. Instead they appear to only become salient when relevant to currently pursued goals." (p. 632). In contrast, traits do seem to stand out as natural groups. Numerous words capture some aspects of the dispositional behavior of individuals. Indeed trait terms are a large part of the language used to describe others, and they play a central role in person perception and attribution. Perhaps traits stand out as natural groups because perceiving, understanding, and communicating the goals of individuals are so central to our goals in social interaction.

\section{Are All Traits Goal-Based?}

The present research suggests that goals are central to the conception of many traits. However, are goals equally important for all traits? Personality researchers have distinguished among a number of kinds of traits, including interpersonal, motivational, stylistic, and expressive traits and temperaments, as well as ability. It seems likely that goals are most important for interpersonal and motivational traits. However, although goals may not be equally important for all traits, we nevertheless believe that all traits can be analyzed in terms of a set of common components: goals, plans, resources, and beliefs (Miller \& Read, 1987, in press; Read \& Miller, 1989).

For interpersonal and motivational traits-such as the ones investigated here-all four components seem highly important. On the other hand, ability traits, such as intelligent, athletic, or socially skilled, can be primarily analyzed in terms of resources and plans, although even here goals may play a role, albeit a lesser one. One important aspect of most people's conception of someone who is intelligent or athletic is that the person in question likes to exercise those abilities and seeks out situations for doing so.

\section{Coherence of Dispositional Categories}

This research begins to provide some insight into what makes the members of a dispositional category hang together or cohere. For at least some traits, associated goals play a major role in their coherence. This is consistent with Alston's (1975) characterization of many traits as purposive-cognitive concepts in which a theoretical framework, typically based on goals or motives, provides the coherence of the category.

Buss and Craik (1983) characterize Alston's position as follows: "Unlike frequency concepts, purposivecognitive concepts do not entail a category of occurrences that can be specified to count as displays of a disposition. Instead they derive their meaning and standing from their place in a theoretical framework (typically motivational in nature) intended to explain behavioral occurrences. Purposive-cognitive concepts include desires, beliefs, and abilities that function within a field of tendencies between activated desires and guiding beliefs on the one hand and manifested behavior on the other" (p. 123).

Alston's view that a theoretical framework provides the basis for the coherence of dispositional categories is quite consistent with some recent views of the nature of 
categories. Theorists such as Murphy and Medin (1985), Wattenmaker, Nakamura, and Medin (1988), and Lakoff (1987) have argued that models of categories that focus on measures of overall similarity, such as family resemblance, are simply inadequate to explain conceptual coherence. They argue that theories, often causal theories, of how the features are related are responsible for conceptual coherence.

The present results provide empirical evidence that a model based on a theoretical framework for a domain seems to capture a large part of what makes trait categories hang together. The model of traits we have offered (Miller \& Read, in press; Read \& Miller, 1989; see also Alston, 1975 ; John, 1986) argues that what makes many traits and trait-related behaviors hang together or cohere is a model of the typical goals, plans, resources, and beliefs of an individual with that trait. Such a model is not a mere feature list but rather a model of how these components are related to one another. For example, individuals should have a model of how particular plans permit the achievement of particular goals, and of what resources are necessary to successfully carry out those plans. A theory or model of the nature of these components and their interrelationships provides the coherence of a trait.

\section{REFERENCES}

Allport, G. W. (1937). Personality: A psychological interpretation. New York: Henry Holt.

ALSTON, W. P. (1970). Toward a logical geography of personality: Traits and deeper lying personality characteristics. In H. D. Krefer \& M. K. Munitz (Eds.), Mind, science, and history (pp. 59-92). Albany, NY: SUNY Press.

ALSTON, W. P. (1975). Traits, consistency and conceptual alternatives for personality theory. Journal for the Theory of Social Behaviour, $5,17-48$.

BARSALOU, L. W. (1985). Ideals, central tendency, and frequency of instantiation as determinants of graded structure in categories. Journal of Experimental Psychology: Learning, Memory, \& Cognition, 11, 629-654.

Buss, D. M., \& Craik, K. H. (1983). The act frequency approach to personality. Psychological Review, 90, 105-126.

Cantor, N., \& Mischel, W. (1977). Traits as prototypes: Effects on recognition memory. Journal of Personality \& Social Psychology, 35, 38-48.

Cantor, N., \& Mischel, W. (1979). Prototypes in person perception. In L. Berkowitz (Ed.), Advances in experimental social psychology (Vol. 12, pp. 3-52). New York: Academic Press.

CARBonell, J. G. (1979). Subjective understanding: Computer models of belief systems (Computer Science Tech. Rep. 150). New Haven: Yale University, Department of Computer Science.

CATtell, R. B. (1965). The scientific analysis of personality. Chicago: Aldine.

JoHN, O. P. (1986). How shall a trait be called: A feature analysis of altruism. In A. Angleitner, A. Furnham, \& G. Van Heck (Eds.), Personality psychology in Europe: Current trends and controversies (pp. 117-140). Berwyn, IL: Swets North America.

LAKOFF, G. (1987). Women, fire and dangerous things: What categories reveal about the mind. Chicago: University of Chicago Press.

Miller, L. C., \& ReAD, S. J. (1987). Why am I telling you this? Selfdisclosure in a goal-based model of personality. In V. J. Derlega \& J. Berg (Eds.), Self-disclosure: Theory, research and therapy (pp. 3558). New York: Plenum.

MilleR, L. C., \& READ, S. J. (in press). Inter-personalism: Understanding persons in relationships. In W. Jones \& D. Perlman (Eds.), Perspectives in interpersonal behavior and relationships (Vol. 2). Greenwich, CT: JAI Press.

MischeL, W. (1973). Toward a cognitive social learning reconceptualization of personality. Psychological Review, 80, 252-283.

MURPHY, G. L., \& MEDIN, D. L. (1985). The role of theories in conceptual coherence. Psychological Review, 92, 289-316.

MurRay, H. (1938). Explorations in personality. New York: Oxford University Press.

Pervin, L. A. (1983). The stasis and flow of behavior: Toward a theory of goals. In M. M. Page (Ed.), Nebraska Symposium on Motivation: 1982 (pp. 1-53). Lincoln: University of Nebraska Press.

READ, S. J., \& MILLER, L. C. (1989). Inter-personalism: Towards a goal based model of persons in relationships. In L. Pervin (Ed.), Goal concepts in personality and social psychology (pp. 413-472). Hillsdale, NJ: Erlbaum.

Rosch, E. (1975). Cognitive reference points. Cognitive Psychology, 7, 532-547.

Rosch, E. (1978). Principles of categorization. In E. Rosch \& B. B. Lloyd (Eds.), Cognition and categorization (pp. 27-48). Hillsdale, NJ: Erlbaum.

Rosch, E., \& Mervis, C. B. (1975). Family resemblances: Studies in the internal structure of categories. Cognitive Psychology, 7, 573-605.

Wattenmaker, W. D., Nakamura, G. V., \& Medin, D. L. (1988). Relationships between similarity-based and explanation-based categorization. In D. J. Hilton (Ed.), Contemporary science and natural explanation: Commonsense conceptions of causality (pp. 204-240). New York: New York University Press. 